\title{
EL «PUZZLE» CONSTITUCIONAL \\ DE ROSS EN EL MARCO TEÓRICO DE LAS REGLAS CONSTITUTIVAS
}

\section{El «puzzle» constitucional de Ross}

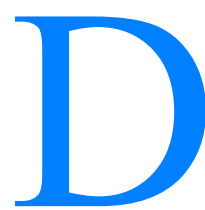

e acuerdo con el artículo 167 de la Constitución española de 1978, «los proyectos de reforma constitucional deberán ser aprobados por una mayoría de tres quintos de cada una de las cámaras» (apartado 1) o, «siempre que el texto hubiere obtenido el voto favorable de la mayoría absoluta del Senado (por) el Congreso por mayoría de dos tercios» (ap. 2). «Aprobada la reforma por las Cortes Generales, será sometida a referéndum para su ratificación cuando así lo soliciten, dentro de los quince días siguientes a su aprobación, una décima parte de los miembros de cualquiera de las Cámaras» (ap. 3).

$\mathrm{Si}$, para simplificar, prescindimos de los restantes artículos del Título $\mathrm{X}$ de la Constitución, el art. 167 sería el único medio jurídico para reformar la Constitución, incluido el propio art. 167; por consiguiente, sería el único medio jurídico para reformar el procedimiento jurídico para la reforma de cualquier artículo de la Constitución, incluido el propio art. 167; por consiguiente, sería el único medio jurídico... y así hasta el infinito.

Por otra parte, sustituir el art. 167 por un hipotético art. 167' significaría lógicamente que, si determinados requisitos (establecidos en el art 167) condicionan la validez de un nueva norma constitucional (el art. 167'), y si esos requisitos se cumplen, de estas dos premisas se deduciría que otros requisitos diferentes (los establecidos en el art. 167') condicionan la validez de una nueva norma constitucional. De esta forma, construiríamos una inferencia lógica contradictoria, porque la conclusión («una nueva norma constitucional sólo es válida si cumple los requisitos establecidos en el art. 167'») contradice la premisa mayor («una nueva norma constitucional sólo es válida si cumple los requisitos establecidos en el art. 167»). 
Mediante estos dos argumentos, Ross presenta la paradoja deóntica de la reforma constitucional autorreferente y contradictoria ${ }^{1}$. De acuerdo con ellos, pueden extraerse tres consecuencias: 1) El art. 167 carece de significado lógico por ser autorreferente; 2) El art. 167 no puede revisarse jurídicamente sin caer en contradicción; 3) En el supuesto de sustitución del art. 167 por el art. 167', es irrelevante que se realice siguiendo o no los requisitos que el propio artículo establece, porque en cualquier caso incumplimos el precepto constitucional. Lo relevante será si, de hecho, las normas constitucionales continúan reformándose según el art. 167 o se reforman según el art. 167'.

Las críticas recibidas por Ross por su «puzzle» constitucional han sido abundantes, y no sólo basadas en presupuestos lógico-normativos, como especialmente en el caso de Hart y Raz ${ }^{2}$, sino incluso también basadas en presupuestos ideológicos, como en el caso de quienes se han escandalizado por el riesgo constitucional que el «puzzle» podría conllevar ${ }^{3}$. No obstante, el ámbito de este trabajo queda limitado al análisis de la paradoja deóntica derivada del «puzzle» desde la perspectiva de la teoría de las reglas constitutivas de Amadeo Conte. En concreto, atribuiré su supuesto carácter paradójico a la confusión acerca de la naturaleza de la norma que regula la reforma constitucional, en algunas ocasiones considerada «regla constitutiva» y en otras ocasiones considerada «regla hipotético-constitutiva».

${ }^{1}$ A. Ross, On Self-Reference and a Puzzle in Constitutional Law, Mind, 78, 1969, págs. 1 a 24. Ross se había referido ya a este «puzzle» constitucional en Om ret og retfaerdighed (Nyt Nordisk Forlag Arnold Busck, Copenhague, 1953), trad. inglesa On Law and Justice (ed. a cargo de M. Knight, trad. de M. Dutton, Stevens, Londres, 1958, págs. 78 y ss.), trad. castellana Sobre el Derecho y la Justicia (trad. de G. Carrió, Eudeba, Buenos Aires, 1963, págs. 76 y ss.).

${ }^{2}$ H. L. A. Hart, Self-Referring Laws, Festskrift tillägnad Karl Olivecrona, Estocolmo, 1964, págs. 307 a 316, y J. Raz, Profesor A. Ross and Some Legal Puzzles, Mind, 81, 1972, págs. 415 a 421. Véase Law, Mind, 81, 1972, págs. 422 a 426; K. Popper, Self-Reference and Meaning, Mind, 6, 1954, págs. 162 y ss.; I. Tammelo y J. Hintikka, The Antinomy of Parliamentary Sovereignty, Archiv für Rechts und Sozialphilosophie, 1958, págs. 495 y ss.; y E. Bulygin, La paradoja de la Reforma Constitucional, Estudios en Homenaje a Alf Ross, ed. a cargo de A. Squella y R. Vernengo, Tomo I, pdgs. 329 a 336, y Time and Validity, en Deontic Logic, Computational Linguistics and Legal Information Systems, ed. a cargo de A. A. Martino, North Holland Publishing Company, Amsterdam-Nueva York-Oxford, 1982 (reeditado con el título Tiempo y validez en C. Alchourron y E. Bulygin, Análisis lógico y Derecho, Centro de Estudios Constitucionales, Madrid, 1991, págs. 195 a 214.

${ }^{3}$ Por ejemplo, R. Guibourg, La autorreferencia normativa y la continuidad constitucional, en El lenguaje del derecho. Homenaje a Genaro Carrió, ed. a cargo de E. Bulygin, M. Farrell, C. Nino y E. Rabossi, Abeledo-Perrot, Buenos Aires, 1983, págs. 181 a 195; véase también C. Nino, Ross y la Reforma del Procedimiento de Reforma Constitucional, en Estudios en Homenaje a Alf Ross, cit., Tomo II, págs. 347 a 364 . 


\section{El concepto y la tipología de las reglas constitutivas}

\section{1. «Reglas regulativas» y « reglas constitutivas» en Searle y Ross}

Dejando al margen precedentes más lejanos, el concepto cotidiano de regla constitutiva coincide en gran medida con el de Searle, quien, basándose en la distinción kantiana entre «principios regulativos»y «principios constitutivos», definió las «reglas regulativas» («regulatives rules») como aquellas que regulan formas de conducta existentes antecedente $\mathrm{o}$ independientemente de dichas reglas, y las «reglas constitutivas» («constitutive-rules») como aquellas que crean o definen nuevas formas de conducta, que «constituyen» una actividad cuya existencia es dependiente, desde el punto de vista lógico, de las reglas ${ }^{4}$. Mientras que las reglas regulativas responden al esquema de las fórmulas «Haz $\mathrm{X}$ » o «Si $\mathrm{Y}$, haz $\mathrm{X} »$, las reglas constitutivas se deben formular «X cuenta como $\mathrm{Y}$ », «X tiene el valor de $\mathrm{Y} »$, «X tiene el sentido de $\mathrm{Y} »(« \mathrm{X}$ counts as $\mathrm{Y} »)$ o «X cuenta como $\mathrm{Y}$ en el contexto $\mathrm{C} »$, , $\mathrm{X}$ tiene el sentido de $\mathrm{Y}$ en el contexto $\mathrm{C} »(« \mathrm{X}$ counts as $\mathrm{Y}$ in context $\mathrm{C} \gg)^{5}$.

Resulta curioso que Ross no conociera esta diferenciación, tal como él mismo aclaró en una nota al margen, cuando escribió «Directives and Norms». Entonces, Ross también habló de reglas regulativas y de reglas constitutivas en el mismo sentido que Searle. Las reglas regulativas prescriben cómo tienen que comportarse sus destinatarios, y los hechos y comportamientos que regulan son «naturales», ya que su ejecución es «independiente lógicamente de las reglas», a las que además anteceden. Las reglas constitutivas también prescriben, en sentido amplio, cómo tienen que comportarse sus destinatarios, pero las relaciones entre regla y regulado son distintas, porque las actividades a las que se refieren no son naturales, sino que se realizan mediante acciones que deben estar de acuerdo con las reglas y que carecen de significado fuera de ese contexto. Las reglas constitutivas definen la actividad sobre la que versan como institución y «proporcionan las condiciones lógicamente necesarias para realizar esa actividad como tal institución» ${ }^{6}$. En palabras de Searle, los hechos que regulan no son «brutos» («brute facts»), sino «institucionales» («institutional facts»), en tanto que su existencia

${ }^{4}$ J. Searle, How to derive «ought» from «is», The Philosophical Review, 73, 1964, págs. 55 y ss., reeditado en The is/ought question, ed. a cargo de W. D. Hudson, McMillan Press, Londres, 1983, p. 132, y Speech Acts. An Essay in the Philosophy of Language, Cambridge University Press, 1969, págs. 33 y 34.

${ }_{5}^{5}$ J. Searle, Speech Acts. An Essay in the Philosophy of Language, cit., págs. 34 y ss.

${ }^{6}$ A. Ross, Directives and Norms, Routledge \& Kegan Paul, Londres, 1968; trad. cast. de J. Hierro Lógica de las normas, Tecnos, Madrid, 1971, págs. 57 y 58. 
presupone la existencia de determinadas instituciones ${ }^{7}$. Un pedazo de papel firmado por quien acaba de fallecer sólo tiene valor -sólo pasa de ser «bruto» a ser «institucional»- en tanto que existe la institución de la sucesión, e incluso, en cierto sentido, sólo podemos interpretar las frases escritas en un testamento en tanto que existe la institución teórica del lenguaje.

\section{2. «Reglas constitutivas» en Conte}

\subsubsection{Definición ontológica y definición semiótica}

Ontológicamente, Conte define las reglas que son el «prius» de aquello sobre lo que versan en el triple sentido de que de ello son condición de concebibilidad, de posibilidad y de perceptibilidad. No versan sobre actos, situaciones o entidades cronológicamente preexistentes ni ontológicamente independientes, sino que en sí mismas constituyen la actividad sobre la que versan y, en ella, su praxis ${ }^{8}$.

Las reglas constitutivas se clasifican, dependiendo de la naturaleza de la condición que las relaciona con lo regulado, en: reglas eidético-constitutivas, que son condición necesaria de aquello sobre lo que versan; reglas thético-constitutivas, que son condición suficiente de aquello sobre lo que versan; y reglas noético-constitutivas, que son condición necesaria y suficiente de aquello sobre lo que versan?.

${ }^{7}$ J. Searle, Speech Acts. An Essay in the Philosophy of language, cit., págs. 50 a 53.

${ }^{8}$ Véanse, entre otros trabajos, A. Conte, Regola constitutiva in Witgenstein, en Uomini senza qualità. La crisi dei linguaggi scientifici nella Vienna degli anni Venti, ed. a cargo de F. Castellani, Departamento de Metodología, Teoría e Historia social, Trento, 1981, págs. 51 a 68; Regola costitutiva, condidone, antinomia, en La teoria generale del diritto. Problemi e tendenze attuali, Estudios dedicados a Norberto Bobbio, Comunità, Milán, 1983, págs. 21 a 39; Phènomènologie du langage déontique, en Les Fondaments logiques de la pensé normative, Actas del Coloquio sobre Lógica Deóntica de Roma (1983), ed. a cargo de G. Kalinowski y F. Salvaggi, Universidad Gregoriana, Roma, 1985, págs. 175 a 191; Materiali per una tipologia delle regole, Materiali per una storia della cultura giuridica, 15, 1985, págs. 345 a 368; y Eidos. An Essay on Constitutive Rules, en Normative Structures of the Social World, ed. a cargo de G. di Bernardo, Rodopi, Amsterdam, 1988, págs. 251 a 257.

${ }^{9}$ La tipología de las reglas -no sólo de las reglas constitutivas, sino también de las reglas hipotético-constitutivas y de las reglas técnicas, en base a la naturaleza de la condición que las relaciona con lo regulado fue esbozada por Conte y ha sido fecundamente desarrollada por su discípulo G. Azzoni en Condizione costitutive, 195, y en Il concetto di condizione nella tipologia delle regole, Cedam, Padua, 1988. En el mismo contexto son asimismo de interés sus trabajos Regola tecnica tra ontico e deontico (Rivista Internazionale di Filosofia del Diritto, 64, 1987, págs. 297 a 321) y Cognitivo e Normativo: il paradosso delle regole tecniche, Franco Angeli, Milán, 1991. 
Semióticamente, las reglas constitutivas son «aquellas que determinan la connotación de los términos que designa la praxis regulada por las reglas» ${ }^{10}$.

De esta doble definición se desprenden dos importantes características de las reglas constitutivas: a) las reglas constitutivas no son posteriores a las situaciones reguladas, no se infieren lógicamente de la experiencia de las acciones que se realizan conforme a ellas, puesto que precisamente son condiciones de posibilidad de esa misma experiencia ${ }^{11}$; b) las reglas constitutivas son inviolables. No seguirlas simplemente significa que el comportamiento en cuestión no se puede interpretar en el contexto de una institución definida por un conjunto de reglas constitutivas, pero sí podría interpretarse en otro contexto. Si muevo el alfil en horizontal en vez de moverlo en diagonal, no violo las reglas constitutivas del ajedrez, sino que me limito a mover un trozo de madera al margen del juego del ajedrez. $\mathrm{Y}$, asimismo, si reunido con mis amigos elaboro normas para todo el país no violo la Constitución, sino que realizo actos que nada tienen que ver con la «institución» de la Constitución.

\subsubsection{La «Norma Fundamental» como regla constitutiva}

¿Es la Norma Fundamental de un ordenamiento una regla constitutiva?, ¿crea o define nuevas formas de conducta, «constituye» una actividad cuya existencia es dependiente, desde el punto de vista lógico, de la propia regla?, ¿es condición de aquello sobre lo que versa?, ¿determina la connotación de los términos que designa la praxis que regula? Creo que la respuesta es afirmativa si nos referimos a la noción kelseniana de Norma Fundamental.

En efecto, ya en «Das Problem der Souveränitaät und die Theorie des Volkerrechts, Kelsen afirma que «este presupuesto jurídico, este punto de partida, esta norma originaria que llamo constitución en sentido lógico-jurídico -en cuanto que determina los órganos supremos del Estado, las fuentes jurídicas supremas- desarrolla plenamente la función de hipótesis fundamental». La Norma Fundamental «no es puesta ni creada consuetudinariamente, sino que ella misma constituye el presupuesto de la normatividad y la costumbre como fuentes del derecho» ${ }^{12}$. En la primera edición de la

${ }^{10}$ A. Conte, Eidos. An Essay on Constitutive Rules, cit., p. 252. Véanse, en el mismo sentido, sus trabajos citados en la nota 8 . págs. 52 y 53 .

${ }^{11}$ A. Conte, Fenomeni di fenomeni, Rivista Internazionale di Filosofia del Diritto, 63, 1986,

${ }^{12}$ H. Kelsen, Das Problem der Souveränität und die Theorie des Völkerrechts, Mogh, Tubinga, 1928, págs. 91 y ss. y nota 8 del Capítulo IV. 
«Reine Rechtslehre», Kelsen insistirá en que la Norma Fundamental no es «puesta» sino «supuesta»; los juicios que atribuyen carácter jurídico a una relación entre individuos «sólo son posibles con la condición general de suponer la validez de una Norma Fundamental ${ }^{13}$. Es condición lógico trascendental de cada norma jurídica objetivamente válida» ${ }^{14}$.

En palabras de Conte, la Norma Fundamental es la regla constitutiva del ordenamiento, no en el sentido de que origina diacrónicamente la validez normativa, sino en el sentido de que origina sincrónicamente cada juicio de validez normativa ${ }^{15}$. En concreto, la Norma Fundamental es una regla noético-constitutiva, puesto que es la única condición necesaria de aquello sobre lo que versa; es de ello condición necesaria y suficiente ${ }^{16}$.

\subsubsection{Reglas constitutivas vs. reglas hipotético-constitutivas}

Junto a las reglas constitutivas, que son condiciones de aquello sobre lo que versan, existe otro conjunto de reglas definible en términos de condición. Se trata de las reglas hipotético-constitutivas, reglas que, desde el punto de vista ontológico ponen condiciones de aquello sobre lo que versan, ponen condiciones para que un acto posea un determinado valor («X debe ser N para contar como $\mathrm{Y} »$, «X debe ser $\mathrm{N}$ para tener el valor de $\mathrm{Y} »)^{17}$.

${ }^{13} \mathrm{H}$. Kelsen, Reine Rechtslehre. Einleitung in die rechtswissen-schafliche Problematik. Deiticke, Viena, 1934; trad. cas. de M. Nilve, Teoría pura del derecho. Introducción a la Ciencia del Derecho. Eudeba, Buenos Aires, 1960, págs. 138 y ss.

${ }^{14}$ H. Kelsen, Reine Rechtslehre, 2. ${ }^{\mathrm{a}}$ ed., Deuticke, Viena, 1960, págs. 204 y ss.

${ }^{15} \mathrm{La}$ «Grundnorm» è non (diacronica) origina della «validità», ma (sincronica) «origo» d’ogni «giudizio di validità». (A. Conte, Fenomeni di fenomeni, cit., pág. 56 y nota 43).

${ }^{16}$ En sus primeros trabajos sobre el tema de las reglas constitutivas, Conte habla de la Norma Fundamental como regla eidético-constitutiva. La razón es exclusivamente conceptual, porque las reglas eidético-constitutivas son entonces conceptuadas como «individualmente condición necesaria, y conjuntamente condición suficiente y necesaria de aquello sobre lo que versan» (Regole Costitutiva, Condizione, Antinomia, cit., pág. 25) y, por consiguiente, la categoría teórica de las reglas noético-constitutivas no se ha desgajado aún de dicho concepto. En Minima Deontica (Rivista Internazionale di Filosofia del Diritto, 65, 1988, nota 15), Conte indica explícitamente que en un ordenamiento «la validez sintáctica queda relativizada a aquella regla noético-constitutiva llamada Norma Fundamental». (Véase también C. Alarcón, Sobre el concepto y tipología de las reglas constitutivas, Anuario de Filosofía del Derecho, VIII, 1991, págs. 278 a 280).

${ }^{17}$ A. Conte, Phénoménologie du langage déontique, cit.., págs, 187 a 190, y Fenomeni di fenomeni, cit., págs. 49 a 51. La distinción en términos ontológicos entre las reglas constitutivas y las reglas hipotético-constitutivas y, en particular, entre las reglas eidético-constitutivas y las reglas anancástico-constitutivas, ha sido cuestionada por M. Jori en In margine all'ultimo Kelsen, Materiali per un storia della cultura giuridica, 16, 1986, págs. 459 y ss. 
Las reglas hipotético-constitutivas se clasifican, dependiendo de la naturaleza de la condición que las relaciona con lo regulado, en: reglas anancástico-constitutivas, que ponen condiciones necesarias de aquello sobre lo que versan; reglas metatético-constitutivas, que ponen condiciones suficientes de aquello sobre lo que versan; y reglas nómico-constitutivas, que ponen condiciones necesarias y suficientes de aquello sobre lo que versan ${ }^{18}$.

Desde el punto de vista semiótico, las reglas hipotético-constitutivas no determinan -como las reglas constitutivas-, sino que presuponen la connotación de los términos que designa la praxis que regulan; es decir, establecen su denotación al poner condiciones de validez de las entidades designadas por estos términos.

\section{El «puzzle» de Ross en términos de constitutividad}

Retomemos el «puzzle» constitucional de Ross e interpretémoslo en el marco de la tipología de las reglas constitutivas reproducida en el epígrafe 2: ¿Es el art. 167 de la Constitución española una regla constitutiva?, ¿es condición de aquello sobre lo que versa?, ¿determina la connotación de los términos que designa la praxis que regula?

En el supuesto de respuesta afirmativa, ¿qué tipo de regla constitutiva es? En el supuesto de que fuera una regla noético-constitutiva, ¿es la Norma Fundamental, en sentido kelseniano, del ordenamiento jurídico español?

En el supuesto de respuesta negativa, ¿es una regla hipotético-constitutiva?, ¿pone condiciones de aquello sobre lo que versa?, ¿presupone la connotación de los términos que designa la praxis que regula, de los cuales establece su denotación? Si así fuera, ¿sería o no una regla nómico-constitutiva?

\section{1. El planteamiento de la paradoja}

3.1.1. El art. 88 de la Constitución danesa como regla noético-constitutiva

\subsubsection{Reglas de competencia y autoridad constitutiva}

Al presentar la paradoja, Ross habla de la regla de revisión constitucional (art. 88 de la Constitución de Dinamarca de 1953) como Norma Fundamental del ordenamiento jurídico, como cúspide de la

${ }^{18} \mathrm{G}$. Azzoni, Il concetto di condijone nella tipologia delle regole, cit., págs. 81 y ss., y Condizione costitutive, cit., págs. 163 y ss. 
pirámide normativa: las normas jurídicas se crean a través de actos de promulgación («enactment») que cumplen las condiciones, personales y procedimentales, establecidas por reglas de competencia. Las reglas de competencia se crean a través de actos que cumplen las condiciones establecidas por reglas de competencia de orden superior, en particular de rango constitucional. Y, finalmente, las normas constitucionales se crean a través de actos que cumplen las condiciones establecidas por la regla que regula la revisión constitucional. Esta regla determina el proceso supremo de producción jurídica y «constituye» la autoridad suprema del ordenamiento, por lo que debe considerarse la Norma Fundamental ${ }^{19}$.

\subsubsection{El «puzzle» de Ross y la paradoja deóntica de la Norma Fundamental}

Como acabo de resaltar, el art. 88 de la Constitución danesa es para Ross, en principio, una regla noético-constitutiva, una regla que es condición necesaria y suficiente del ordenamiento jurídico, una regla que determina la connotación de los términos que designan las normas jurídicas. Y, en tanto que Norma Fundamental del ordenamiento, su carácter paradójico estaría en relación con la propia paradoja deóntica de la Norma Fundamental. Conforme a esta paradoja, la Norma Fundamental, al establecer que toda norma debe fundar su validez en una norma superior, establece su propia invalidez, ya que no existe ninguna norma superior a la Norma Fundamental. Reformulada en términos de una teoría de la validez, la paradoja deóntica de la Norma Fundamental se convierte en aporía: una teoría de la validez basada en que toda norma debe fundar su validez en una norma superior no tiene sentido si la norma suprema no posee fundamento de validez, lo que sucesivamente provoca la invalidez de todas las normas del ordenamiento ${ }^{20}$.

De acuerdo con el planteamiento de Ross, parecería entonces que la paradoja provocada por la reforma del art. 88 hereda las contradicciones de la paradoja y de la aporía de la Norma Fundamental, y a ellas les añade las suyas propias. Si sustituimos el art. 88 por un hipotético art. 88', nos enfrentamos al problema de que la nueva Norma Fundamental no funda tampoco su validez en una norma superior; la funda en una norma no superior -el art. 88- que establece

${ }^{19}$ A Ross, On Self-Reference and a Puzzle in Constitucional Law, cit., págs. 1 y ss.

${ }^{20}$ Véase A. Conte, Ricerca dun paradosso deontico. Materiali per una semantica del linguaggio normnativo, Rivista Internazionale di Filosofia del Diritto, 51, págs. 501 y 502. 
unas pautas de validez precisamente incompatibles con las que establece el propio art. 88'.

\subsubsection{El art. 88 de la Constitución danesa como regla nómico-constitutiva}

Considerar la regla que regula la revisión constitucional como la Norma Fundamental del ordenamiento agrava, a primera vista, la paradoja que se analiza. No obstante, en mi opinión el problema no surge porque Ross considera que el art. 88 de la Constitución de Dinamarca es la Norma Fundamental del ordenamiento jurídico danés, sino porque Ross no es coherente con tal consideración cuando pretende demostrar la autorreferencia y el carácter contradictorio del mencionado artículo.

\subsubsection{La autorreferencia del art. 88}

El art.88 de la Constitución es el único cauce jurídico para la reforma de cualquier precepto constitucional, incluido el propio art. 88. A juicio de Ross, el art. 88 carece de significado, de acuerdo con la «teoría de los tipos» de Bertrand Russell, porque atribuye un predicado a una expresión construida en un determinado lenguaje por medio de otra expresión construida en el mismo lenguaje, y no en un lenguaje de orden superior, en un metalenguaje. La paradoja surge por aceptar que una sucesión de objetos puede contener miembros sólo definibles mediante la sucesión en su totalidad ${ }^{21}$. De hecho, el art. 88 se podría intentar expresar del siguiente modo: «el art. 1 de la Constitución (que establece que...) puede modificarse a través del procedimiento P; el art. 2 de la Constitución (que establece que...) puede modificarse a través del procedimiento $\mathrm{P} ; \ldots$ el art. 88 de la Constitución (que establece que el art. 1 de la Constitución [que establece que...] ...)» ${ }^{22}$. El art. 88 no podría nunca terminar de formularse (no podría «usarse», no podría expresarse lingüísticamente) porque cada vez que se citara (cada vez que «se mencionara», cada vez que se expresara metalingüísticamente) debería iniciarse la serie.

Así formulado, el art. 88 no determina la connotación de los términos que designa la praxis que regula, no alude a las características o propiedades de los objetos a los que se refiere, sino al conjunto de objetos en sí mismos, respecto a los cuales presupone su connotación y establece su denotación. A pesar de comenzar hablando del

${ }^{21}$ A. Ross, On Self-Reference and a Puzzle in Constitucional Law, cit., págs. 7 y ss.; véase también R. Guibourg, La autorreferencia normativa y la continuidad constitucional, cit., págs. 184 y ss.

${ }^{22}$ A. Ross, On Self-Reference and a Puzzle in Constitutional Law, cit., págs. 9 y ss. 
art. 88 como Norma Fundamental, como regla noético-constitutiva, Ross lo formula como una regla hipotético-constitutiva, como una regla que pone condiciones de aquello sobre lo que versa; en particular, como una regla nómico-constitutiva, como una regla que pone condiciones necesarias y suficientes de aquello sobre lo que versa.

\subsubsection{La inferencia contradictoria basada en el art. 88}

Además de autorreferente, el art. 88 es, para Ross, contradictorio porque su modificación exige a la vez el cumplimiento de los requisitos que establece y el cumplimiento de requisitos diferentes establecidos por el art. 88'. Una inferencia correcta que concierna a una regla válida creada a través de un procedimiento previamente establecido alude, como premisa mayor, a las condiciones de validez puestas por una regla de competencia; como premisa menor, al cumplimiento de dichas condiciones; y, como conclusión, a la validez de la norma creada. Pero la validez del art. 88' estaría basada en la inferencia que Ross construye así:

1. «Art. 88: La constitución puede modificarse a través de un procedimiento que debe estar de acuerdo con las condiciones $\mathrm{C} 1, \mathrm{C} 2$ y C3, y sólo a través de este procedimiento.»

2. «El art. 88' (que establece que la Constitución puede modificarse a través de un procedimiento que debe estar de acuerdo con las condiciones $\mathrm{C} 1$ ', $\mathrm{C} 2$ ' y C3', y sólo a través de este procedimiento) ha sido creado de conformidad con las condiciones $\mathrm{C} 1, \mathrm{C} 2$ y $\mathrm{C} 3 . »$

3. «El art. 88' es válido, por lo que la Constitución puede modificarse a través de un procedimiento que debe estar de acuerdo con las condiciones $\mathrm{C} 1$ ', $\mathrm{C} 2$ ' y C3', y sólo a través de este procedimiento.. ${ }^{23}$

A juicio de Ross, esta inferencia es lógicamente absurda porque la conclusión contradice la premisa mayor. No me interesa de momento discutir si Ross tiene o no razón, ni tampoco cuestionar la inferencia por relacionar enunciados descriptivos con enunciados prescriptivos, sino resaltar que, tal como es formulado en la premisa mayor, el art. 88 no es una regla noético-constitutiva, no es condición necesaria y suficiente de aquello sobre lo que versa, no determina la connotación de los términos que designa la reforma constitucional, sino que pone condiciones necesarias de aquello sobre lo que

${ }^{23}$ Ibid., págs. 4 y ss. 
versa, presupone la connotación y determina la denotación de la reforma constitucional, de la cual pone condiciones de validez. En contra de lo que el propio Ross había afirmado anteriormente, el art. 88, así formulado, no es la Norma Fundamental del ordenamiento jurídico danés.

\subsubsection{Validez sintáctica vs. validez pragmática}

La confusión creada por la ambigua naturaleza del art. 88 puede combatirse de modo más certero si hacemos referencia a la reciente distinción entre «validez sintáctica» y «validez pragmática» que debemos a Conte.

La validez sintáctica, relativa a status deónticos (obligaciones, prohibiciones, permisiones), depende de las reglas constitutivas de un ordenamiento, las cuales, «al condicionar la validez de status deónticos «en» el ordenamiento y «por» el ordenamiento, de dicho ordenamiento determinan la sintaxis de validez $\rangle^{24}$.

La validez pragmática, relativa a actos deónticos, depende de las reglas hipotético-constitutivas de un ordenamiento, las cuales «ponen» o instauran condiciones «en» un ordenamiento y «por» un ordenamiento para que un acto posea un determinado valor $^{25}$.

Cuando Ross, al comienzo de su exposición, considera el art. 88 como la Norma Fundamental del ordenamiento jurídico danés y discute el problema del fundamento de su validez, asume implícitamente el art. 88 como condición de validez sintáctica, validez cuestionada por la paradoja y por la aporía de la Norma Fundamental. Cuando construye la inferencia contradictoria y analiza la autorreferencia del art. 88, Ross asume implícitamente el art. 88 como condición de validez pragmática; esto es, como regla hipotético-constitutiva, $\mathrm{y}$, en concreto, como regla nómico-constitutiva, como regla que pone condiciones necesarias y suficientes de aquello sobre lo que versa.

\subsection{La solución de la paradoja}

Si aceptamos que el art. 88 de la Constitución danesa es una regla nómico-constitutiva, y no una regla noético-constitutiva, evitamos las consecuencias de la paradoja y de la aporía de la Norma Fundamental. Pero, aparentemente, la paradoja de la regla de reforma constitucional sigue en pie; la autorreferencia y la contradictoria

${ }^{24}$ A. Conte, Minima Deontica, cit., pág. 436.

${ }^{25}$ Ibid., págs. 431 y ss. 
validez del art. 88 no se superan por el mero hecho de descartar su carácter de Norma Fundamental.

A diferencia del planteamiento inicial de Ross, que a mi juicio es ambiguo y confuso por presentar el art. 88 indistintamente como regla noético-constitutiva y como regla nómico-constitutiva, creo que la solución que el propio Ross ofrece para resolver la paradoja es acertada.

\subsubsection{Normas y metanormas}

Al presentar su propuesta de solución de la paradoja, Ross parte de que en los sistemas normativos deductivos no existe ningún procedimiento jurídico para reformar la Norma Fundamental, que como base última de todas las deducciones no es en sí misma deducible. Pero, como ahora sí acepta Ross explícitamente, el art. 88, aunque constituye la autoridad suprema del ordenamiento jurídico, puede no ser la Norma Fundamental. Puede existir una norma superior que, a pesar de no establecer ningún procedimiento para revisar el art. 88 ni constituir una autoridad superior a la constituida por el art. 88, sea la Norma Fundamental del sistema en tanto que confiera al art. 88 una validez condicional. La Norma Fundamental no transferiría la competencia de constituir la autoridad suprema del ordenamiento jurídico al art. 88 , sino que «delegaría» tal competencia sin perderla ${ }^{26}$.

Entendido como regla nómico-constitutiva, como regla que no es condición necesaria y suficiente de la validez normativa -ya que está condicionada por la Norma Fundamental, por una regla noético-constitutiva-, sino que pone condiciones necesarias y suficientes de la validez normativa, el art. 88 no es autorreferente porque se refiere a la Norma Fundamental. No carece de significado porque atribuye un predicado a una expresión lingüística a través de otra expresión construida en un metalenguaje, en un lenguaje de diferente nivel. Como ha indicado Conte, para expresar el carácter non-nativo o deóntico de un sistema no se puede recurrir al propio lenguaje normativo. Un conjunto de normas forma un sistema normativo si, y sólo si, tienen un único y mismo fundamento de validez, pero el criterio de validez no es en sí mismo una norma jurídica -por ejemplo, una regla nómico-constitutiva como el art. 88-, sino una norma metajurídica, una regla noético-constitutiva, que se expresa a un nivel lingüístico diferente ${ }^{27}$.

${ }^{26}$ A. Ross, On Self-Reference and a Puzzle in Constitutional Law, cit., págs. 19 y ss.

${ }^{27}$ A. Conte, Codici deontici, en Intorno al «codice», Actas del III Congreso de la Asociación Italiana de estudios semióticos (Pavía, septiembre 1975), La Nuova Italia, Florencia, 1976, págs. 19 a 21 . 
Pensemos de nuevo en el art. 167.1 de la Constitución española y prescindamos a efectos teóricos, para simplificar aún más, de los apartados 2 y 3 :

Art. 167.1: «Los proyectos de reforma constitucional deberán ser aprobados por una mayoría de tres quintos de cada una de las Cámaras».

El art. 167.1 no es -aunque aceptemos, como hipótesis, que sea la única norma del Título X de la Constitución- la Norma Fundamental del ordenamiento jurídico español, sino que presupone una norma tácita, que sí sería propiamente la Norma Fundamental, y que podría explicitarse así:

«Se debe seguir el procedimiento establecido en el art. 167.1 de la Constitución para reformar o crear normas constitucionales hasta que a través de dicho procedimiento se establezca un procedimiento diferente; entonces se debe seguir este último procedimiento hasta que a través del mismo se establezca un procedimiento diferente, y así sucesivamente.»

Esta norma tampoco es autorreferente, porque se refiere al art. 167.1. Como regla noético-constitutiva es condición necesaria y suficiente del fenómeno jurídico español, determina la connotación de los términos designados por la praxis jurídica que regula. Dicha connotación es presupuesta por el art. 167.1, que, como regla nómico-constitutiva, establece la denotación de esos términos al poner condiciones necesarias y suficientes de validez de las normas jurídicas.

Supongamos que los legisladores deciden sustituir el art. 167.1 por el art. 167.1':

Art. 167.1': «Los proyectos de reforma constitucional deberán ser aprobados por mayoría simple del Congreso de Diputados».

La inferencia de validez normativa del art. 167.1 ' se construiría así:

(1') Se debe seguir el procedimiento establecido en el art. 167.1 de la Constitución para reformar o crear normas constitucionales hasta que a través de dicho procedimiento se establezca un procedimiento diferente; entonces se debe seguir este último procedimiento hasta que a través del mismo se establezca un procedimiento diferente, y así sucesivamente. 
(2') Se crea el art. 167.1' siguiendo lo establecido en (1') (es decir, se cumplen las condiciones citadas en el art. 167.1 para establecer el procedimiento al que se refiere el art. 167.1'.

(3’) El art. 167.1' es una norma constitucional válida.

(1') no es la citada Norma Fundamental, sino una proposición sobre la Norma Fundamental sintácticamente idéntica a ella. De hecho, esta proposición podría reformularse explicitando el contexto en el que se enmarca (la creación de normas constitucionales válidas de acuerdo con la Norma Fundamental), con lo que resaltaría su carácter metalingüístico.

(1') Para crear una norma constitucional válida, de acuerdo con la Norma Fundamental, se debe seguir el procedimiento establecido en el art. 167.1 de la Constitución para reformar o crear normas constitucionales hasta que a través de dicho procedimiento se establezca un procedimiento diferente; entonces se debe seguir este último procedimiento hasta que a través del mismo se establezca un procedimiento diferente, y así sucesivamente.

La inferencia es válida, ya que la conclusión (3') se deduce de las premisas (1') y (2') y no contradice ninguna de ellas; en particular, no contradice la premisa mayor -como sí ocurría en la inferencia construida por Ross (citada en 3.1.2.2)- porque ésta no alude a la norma que regula la revisión constitucional, sino a la Norma Fundamental del ordenamiento. Además, es una inferencia compuesta exclusivamente de premisas proposicionales y, por consiguiente, no plantea problemas desde el punto de vista de la «Gran División» entre «ser» $\mathrm{y} \ll$ debe ser» ${ }^{28}$.

En resumen, si se despejan las dudas sobre la naturaleza nómico-constitutiva de la regla de revisión constitucional, y sobre su dependencia respecto a una regla noético-constitutiva, se puede afirmar que la inferencia de validez deóntica del art. 167.1 es dianoéticamente válida ${ }^{29}$.

${ }^{28} \mathrm{Me}$ he ocupado de esta cuestión en C. Alarcón, En torno a la lógica deóntica del último Kelsen, Anuario de Filosofía del Derecho, Tomo VI, 1989, págs. 313 a 337.

${ }^{29}$ Véase A. Conte, Deóntico vs. Dianoetico, Materiali per una storia della cultura giuridica, 16, 1986, págs. 489 a 494. Conte destaca que la validez deóntica de una norma («Geltung») no depende de las normas respecto a las cuales la norma posee validez dianoética o inferencial («Gultgkeit»), sino de las metarreglas o reglas constitutivas que condicionan la validez deóntica «en» un ordenamiento y «por» un ordenamiento (Ibid., pág, 491). 


\subsubsection{Guastini contra Ross}

\subsubsection{Dos argumentos contra la solución de Ross}

Para R. Guastini, la explicación ofrecida por Ross es excesivamente ambiciosa porque emplea medios desproporcionados respecto a sus fines: a la vez que se dirige contra la paradoja y la aporía de la Norma Fundamental. En concreto, no está de acuerdo con Ross por dos razones:

A) Para resolver la paradoja de la regla de revisión constitucional no es necesario apelar a una norma superior al art. 167.1 de la Constitución española (obviamente, traslado a la Constitución española las referencias de Guastini al art. 138 de la Constitución italiana). Sería suficiente reformular el art. 167.1 mediante la explicitación de la Norma Fundamental tácita del ordenamiento jurídico español ${ }^{30}$ :

«Para reformar o crear normas constitucionales los proyectos deberán ser aprobados por una mayoría de tres quintos de cada una de las Cámaras hasta que a través de dicho procedimiento se establezca una procedimiento diferente; entonces se debe seguir este último procedimiento hasta que a través del mismo se establezca un procedimiento diferente, y así sucesivamente.»

B) Apelar a una norma tácita superior al art. 167.1 puede servir para fundamentar su validez y, si el art. 167.1 es considerado la Norma Fundamental, para resolver la aporía de la Norma Fundamental, pero no sirve para resolver la paradoja de la regla de revisión constitucional, porque el art. 167.1 continúa siendo autorreferente y contradictorio ${ }^{31}$.

En definitiva, para Guastini, la Norma Fundamental tácita a la que hace referencia Ross es una reiteración de la Norma Fundamental expresa, empírica (en el ordenamiento jurídico español, del art. 167.1 de la Constitución). La solución de la paradoja no debe seguir ese rumbo, sino partir de que el art. 167.1, aunque desde el punto de vista empírico es parte material de la Constitución, desde

${ }^{30}$ R. Guastini, Questioni di deontica en Ross. Con un'appendice bibliografica sulla fortuna di Ross in Italia, Materiali per una storia della cultura giuridica, 11, 198 1, págs. 493 y ss., reeditado parcialmente con el título Problemi d'analisi del linguaggio normativo como estudio preliminar de A. Ross, Critica del diritto e analisi del linguaggio, ed. a cargo de A. Febbrajo y R. Guastini, Il Mulino, Bolonia, 1982, págs. 47 a 69 (véase las págs. 60 a 64).

${ }^{31}$ R. Guastini, Questioni di deontica in Ross. Con un'appendice bibliografica sulla fortuna di Ross in Italia, cit., pág. 496. 
el punto de vista lógico se sitúa a un nivel metalingüístico y supraconstitucional, por lo que no se puede aplicar para reformarse a sí mismo: «la norma del art. 138 (de la Constitución italiana) es la norma constitutiva del juego llamado «ordenamiento jurídico italiano». Por más que nos digan los juristas, el cambio de esta norma, ocurriera como ocurriera (incluso en la forma que la propia norma prescribe) fundaría un juego distinto» ${ }^{32}$.

\subsubsection{Crítica de la crítica de Guastini}

\subsubsection{Crítica del primer argumento de Guastini contra Ross}

Como se deduce de su primer argumento crítico contra Ross, Guastini considera que la paradoja en cuestión se evitaría si el art. 138 de la Constitución italiana (y, análogamente, el art. 167.1 de la Constitución española) se identificara con la propia Norma Fundamental, se reformulara en términos de Norma Fundamental. La posición de Guastini es, entonces, similar a la mantenida por Ross al explicar la paradoja al comienzo de su exposición, e incurre también en el error de considerar a la vez la regla de reforma constitucional como regla noético-constitutiva y como regla nómico-constitutiva.

\subsection{El problema de la autorreferencia en la tesis de Guastini}

Con una naturaleza tan ambigua, el art. 167.1 de la Constitución española no puede librarse de la autorreferencia ni aludiendo a una norma superior -puesto que ella misma es la norma suprema del ordenamiento, es condición necesaria y suficiente de todo el ordenamiento y no está condicionada por ninguna otra norma-, ni aludiendo a una norma inferior, ya que es también en sí misma una norma más del ordenamiento, una regla nómico-constitutiva condicionada, como las restantes normas, por una regla noético-constitutiva, por la Norma Fundamental del ordenamiento. Los dos niveles lingüísticos se mezclarían en el mismo enunciado normativo, que quedaría sin significado por ser autorreferente.

\subsection{El problema de la inferencia contradictoria en la tesis de Guastini}

La validez del hipotético art. 167.1' se basaría, de aceptar la tesis de Guastini, en una inferencia lógica que sería contradictoria, aunque

${ }^{32}$ Ibid., págs. 496 y 497. 
no exactamente por los mismos motivos que la inferencia presentada por Ross para demostrar el sentido paradójico del art. 88 de la Constitución danesa.

La inferencia de Ross es contradictoria por contener como premisa mayor el art. 88 de la Constitución danesa, pero, de acuerdo con el planteamiento de Guastini, la inferencia de validez normativa del art. 167.1' no tendría como premisa mayor el art. 167 de la Constitución española, sino una proposición sobre el art. 167. Posiblemente, Guastini confiaría en esta solución porque de esta forma en la inferencia ya no se deduciría una conclusión descriptiva a partir de una premisa mayor prescriptiva, como sí ocurría en la inferencia construida por Ross. Sin embargo, esta irregularidad, aunque podría provocar la incorrección de la inferencia por no respetar la «Gran División», no es la causante de su carácter contradictorio. Para salvar la contradicción, no basta con enunciar descriptivamente la premisa mayor, sino que ésta debe aludir descriptivamente a una norma superior al art. 167.1' que constituya su criterio de validez. La inferencia basada en el planteamiento de Guastini coincidiría con la que Ross construye posteriormente, al solucionar la paradoja, y con la que he construido en 3.2.1, en que la premisa mayor sería proposicional, no normativa, pero coincidiría con la construida por Ross al exponer la paradoja en que la premisa mayor alude a una regla nómico-constitutiva, no a una regla noético-constitutiva. Por lo tanto, sería una inferencia semánticamente homogénea, en el sentido de deducir una conclusión proposicional de dos premisas proposicionales, pero no dejaría de ser contradictoria.

\subsubsection{Crítica del segundo argumento de Guastini contra Ross}

De acuerdo con el segundo argumento de Guastini, tan autorreferente y contradictorio es el art. 167.1 de la Constitución española considerado regla constitutiva (en concreto, regla noético-constitutiva) como considerado regla hipotético-constitutiva (en concreto, regla nómico-constitutiva). Sin embargo, no hay que olvidar que este artículo tiene la peculiaridad de que, justamente en virtud de su seguimiento, puede dejar de existir sustituyéndose por otro, posibilidad que contradice la noción de regla constitutiva como condición de aquello sobre lo que versa: las reglas constitutivas no pueden ser posteriores a las situaciones reguladas ni inferirse lógicamente de la experiencia de las acciones que se realizan conforme a ellas. Como ha resaltado Conte, el contenido específico de una regla constitutiva puede ser alterado, al igual que el contenido específico de una regla hipotético-constitutiva, por el seguimiento de la propia regla (por 
ejemplo, la regla constitutiva «Añadir un número al último número de la serie $\mathrm{S}$ vale como prosecución de $\mathrm{S}$ si el número añadido es superior a todos los números incluidos en $\mathrm{S}$ » ve alterado su contenido específico cada vez que se realiza una acción siguiendo la regla ${ }^{33}$ ), pero la regla constitutiva en sí misma no puede ser alterada por su propio seguimiento. Cuando el art. 167.1 se aplica a sí mismo no cambia el contenido específico de la regla, sino que cambia la propia regla, siendo sustituida por otra, por el art 167.1', por lo que no puede ser una regla constitutiva.

A diferencia de las reglas constitutivas, las reglas hipotético-constitutivas, como reglas que no son condiciones, sino que ponen condiciones de aquello sobre lo que versan, sí pueden ser sustituidas por otras en virtud de una acción realizada siguiendo las propias reglas, ya que pueden regular realidades preexistentes; en concreto, realidades concebibles, posibles y perceptibles en tanto que han sido constituidas por reglas constitutivas, como por ejemplo la praxis de la reforma constitucional.

En resumen, el art. 167.1 como regla hipotético-constitutiva, y en concreto como regla nómico-constitutiva, no es paradójico si se refiere a una regla noético-constitutiva. La supuesta autorreferencia y el supuesto carácter contradictorio del art. 167.1 no sólo dependen, como parece deducirse de la tesis de Guastini, de sus características internas, sino, sobre todo, de cómo se relaciona con las restantes normas del ordenamiento y, en particular, con la Norma Fundamental. G. Azzoni ha destacado que, con su crítica a Ross, Guastini, implícitamente, propone una forma diferente de considerar la Norma Fundamental desde la perspectiva de la teoría de las reglas constitutivas: como regla nómico-constitutiva ${ }^{34}$. A mi juicio no es así: en tanto

${ }^{33}$ A. Conte, Parerga Leibnitiana, en Logica, Informatica, Diritto, ed. a cargo de C. Ciampi, E. Maretti y A. Martino, Le Monnier, Florencia, 1978, Tomo I, págs. 241 a 244. En este trabajo, Conte comenta la asimetría entre las reglas constitutivas y las reglas regulativas (Conte consideraba aún las reglas regulativas, ampliamente, como reglas no constitutivas, y por tanto incluyendo en ellas las reglas hipotético-constitutivas) en el siguiente sentido: el contenido específico de una regla no constitutiva puede alterarse por una acción a través de la cual se cumpla la regla no constitutiva y por una acción a través de la cual se incumpla la regla no constitutiva; el contenido específico de una regla constitutiva puede alterarse por una acción a través de la cual se incumpla la regla constitutiva. Por mi parte, trataré de explicitar un segundo sentido de la mencionada asimetría que en Parerga Leibnitiana (Ibid., nota 56) parece ser sólo implícito: una regla no constitutiva puede ser sustituida por otra regla no constitutiva por una acción a través de la cual se cumpla la primera regla no constitutiva; una regla constitutiva no puede ser sustituida por otra regla constitutiva por una acción a través de la cual se cumpla la primera regla constitutiva.

${ }^{34} \mathrm{G}$. Azzoni, Il concetto di condizione nella tipologia delle regole, cit., págs. 78 y 79. 
que regla nómico-constitutiva, el art. 167.1 no puede ser la Norma Fundamental sino una norma condicionada por la Norma Fundamental; en tanto que Norma Fundamental, el art. 167.1 no podría ser una regla nómico-constitutiva, sino una regla noético-constitutiva (que además carecería de sentido por ser autorreferente y contradictoria). La paradoja se soluciona si se concibe el art. 167.1 como regla nómico-constitutiva, pero no como Norma Fundamental, sino como regla que es válida y puede seguirse en el contexto de la Norma Fundamental, en el contexto de una regla noético-constitutiva.

$\mathrm{Si}$, como acabamos de señalar, el problema de la paradoja de la regla de revisión constitucional no sólo depende de las características internas de la regla (en concreto, de su naturaleza nómico-constitutiva), sino también de su relación con la Norma Fundamental del ordenamiento, debemos rechazar el segundo argumento crítico de Guastini, no sólo resaltando la importancia de apelar a una norma tácita en cuyo contexto se interprete la regulación de la reforma constitucional, sino asimismo reconociendo la conexión entre la paradoja de la regla de revisión constitucional y la aporía de la Norma Fundamental.

En este sentido, llama la atención que sea precisamente en base a la «teoría de los tipos» de Russell como Conte soluciona la aporía de la Norma Fundamental. Para Conte, esta aporía no sólo se puede evitar a través del concepto kelseniano de Norma Fundamental («la Norma Fundamental es válida, en cuanto que, aunque no sigue pautas de validez fijadas en ninguna otra norma, es presupuesta válida como hipótesis lógico-trascendental»), sino también afirmando que la Norma Fundamental no es ni válida ni inválida; simplemente define la expresión «norma válida» ${ }^{35}$. A diferencia de las restantes normas del ordenamiento, incluida la regla constitucional que pone condiciones suficientes y necesarias de la reforma constitucional, la Norma Fundamental es conceptualmente autorreferente. En palabras de

${ }^{35}$ A. Conte, Validità, en Novissimo digesto italiano, UTET, Turín, 1975, vol. XX, págs. 418 a 425; reeditado en A. Conte, Filosofia del Linguaggio nonnativo I. Studi 1965-1981, G. Giappichelli, Turín, 1989, págs. 119 a 145 (en particular, véanse págs. 135 a 137). Para Conte, la Norma Fundamental no es válida ni inválida, sino que define la validez, establece los criterios para determinar si las restantes normas del ordenamiento son o no son válidas. La Norma Fundamental es semejante a la barra que define lo que es el metro, que sirve para medir cualquier distancia en metros, pero que no se puede, a su vez, medir en metros, porque no «tiene» la longitud de un metro, sino que «es» la longitud de un metro. Si por algún cambio de temperatura se alargara o se acortara, la barra seguiría midiendo un metro a pesar de ser más larga o más corta que antes. La Norma Fundamental tampoco «tiene» validez, sino que «es» validez, y, si cambia, seguirá «siendo» validez (A. Conte, Studio per una teoria della validità, Rivista Internazionale di Filosofia del diritto, 47, 1970, págs. 341 y ss., reeditado con algunas modificaciones en Problemi di teoria del diritto, ed. a cargo de R. Guastini, Il Mulino, Bolonia, 1980, pág. 339). 
Kant, quien, como ha destacado Conte, debe considerarse origen sincrónico y «origo» diacrónico de la teoría de la Norma Fundamental y de la teoría de las reglas constitutivas, «la razón ve sólo lo que ella misma, según su propio diseño, produce». Como regla noético-constitutiva, la Norma Fundamental, al igual que la razón humana, tampoco ve más que lo que ella misma, según su propio diseño, produce ${ }^{36}$.

${ }^{36}$ A. Conte, Minima Deontica, cit., nota 15. 